\title{
Seasonal Assessment of Nitrate, Nitrite, and Heavy Metals Pollution in Groundwater of Ardabil Aquifer, Iran
}

\author{
Vahid Rezaverdinejad*, Mina Rahimi \\ Department of Water Engineering, Urmia University, Urmia, Iran
}

Received: 3 October 2016

Accepted: 28 March 2017

\begin{abstract}
One of the most important resources for drinking water is groundwater. Recently, the quality of groundwater has been endangered due to several reasons, including human activities, vast agricultural activities, and the discharge of industrial wastewater containing nitrogen $(\mathrm{N})$ and heavy metals. For this study we investigated the values of $\mathrm{NO}_{3}, \mathrm{NO}_{2}$, and some heavy metals and analyzed the groundwater of the Ardabil Aquifer area in wet and dry seasons. For this purpose we evaluated 76 wells in the study area. In order to analyze the results we used World Health Organization (WHO), U.S. Environmental Protection Agency (EPA), and Institute of Standard and Industrial Research of Iran (ISIRI) standards. The results indicated that, according to WHO and ISIRI, $10.5 \%$ of wells and, according to the EPA, $69.7 \%$ of wells have $\mathrm{NO}_{3}$ above the standard level in the wet season, but in the dry season, according to WHO and ISIRI, $29 \%$ and, according to the EPA, $80.6 \%$ of the wells have $\mathrm{NO}_{3}$ above the permissible level. However, according to all standards, $\mathrm{NO}_{2}$ values are less than the permissible level for drinking consumption. In terms of evaluation criteria of the simultaneous presence of $\mathrm{NO}_{3}$ and $\mathrm{NO}_{2}$ in drinking water $(\mathrm{K}), 29 \%$ of wells in the dry season and $13.15 \%$ of wells in the wet season have $\mathrm{NO}_{3}$ and $\mathrm{NO}_{2}$ problems. In order to find an appropriate interpolation method and zoning parameter of $\mathrm{NO}_{3}$ and $\mathrm{NO}_{2}$, different interpolation methods were evaluated and Kriging method with the lowest error was chosen for zoning the parameters. According to zoning maps, in the wet season the Namin and south Ardabil areas, which have the most drinking water wells, contain values of $\mathrm{NO}_{3}$ above the permissible levels, whereas the values of $\mathrm{NO}_{3}$ are at the mediocre level in the dry season. In addition to $\mathrm{NO}_{3}$ and $\mathrm{NO}_{2}$ analysis, the evaluation of heavy metals pollution indices in the aquifer include: heavy metal pollution index (HPI), heavy metal evaluation index (HEI), and contamination degree $\left(\mathrm{C}_{\mathrm{d}}\right)$. Generally, according to the EPA, in terms of $\mathrm{NO}_{3}$ and $\mathrm{NO}_{2}$ pollution, Ardabil aquifer is in an undesirable condition, and according to WHO and ISIRI standards, this area has a mediocre level of undesirable condition. According to HPI and $\mathrm{C}_{\mathrm{d}}$ indices, most parts are in a high class of heavy metal pollution, as well.
\end{abstract}

Keywords: groundwater, heavy metals, Kriging, monitoring, nitrate

*e-mail: v.verdinejad@urmia.ac.ir 


\section{Introduction}

Due to the unreliability and inaccessibility of surface water resources, groundwater consumption has increased. Currently, groundwater is considered one of the biggest resources of drinking water and industrial consumption [1-2]. Groundwater quality is in danger due to various human activities, including agriculture and industry. The existence of elements with higher poisoning levels in groundwater is related to the disposal of industrial wastewater containing nitrogen (N) [3-5]. Groundwater pollution by sewage has been reported by many researchers [6-10]. Such contamination has led to serious problems in areas where groundwater is the main source of drinking water consumption. According to studies in 1990, 0.8 million people in France, 0.85 million people in England, and 2.5 million people in Germany were in danger of water contamination by $\mathrm{NO}_{3}$ [11-12]. Three pollutants, including $\mathrm{NO}_{3}, \mathrm{NO}_{2}$, and ammonium nitrogen $\left(\mathrm{NH}_{4}\right)$, are $\mathrm{N}$ derivations [13-14]. $\mathrm{NO}_{3}$ is necessary for agriculture products and it is obtained from $\mathrm{N}$ residing in the soil or $\mathrm{N}$ fertilizers [15]. $\mathrm{NO}_{2}$ is known as the final product of oxidation of $\mathrm{N}$ compounds, and with the presence of reducing bacteria's digestive system and appropriate $\mathrm{pH}$ in the digestive system, it is changed into $\mathrm{NO}_{2}$, which leads to methemoglobinemia (MetHb) disease [16]. According to the latest guidelines of $\mathrm{WHO}$ and the latest standard of ISIRI, the maximum allowable amounts of $\mathrm{NO}_{3}$ and $\mathrm{NO}_{2}$ in drinking water are $50 \mathrm{mg} / \mathrm{L}$ and $3 \mathrm{mg} / \mathrm{L}$, respectively $[5,11]$. High levels of $\mathrm{NO}_{3}$ concentrations in water shows pollution that can also contain microbial contamination [17]. According to $\mathrm{WHO}$, due to the possibility of the simultaneous existence of $\mathrm{NO}_{3}$ and $\mathrm{NO}_{2}$ in drinking water, the total measured values of $\mathrm{NO}_{3}$ and $\mathrm{NO}_{2}$ are divided into the proposed guideline values, $\mathrm{K}$, which must be less than $1[11]$ :

$$
K=\frac{N O_{3}}{S_{1}}+\frac{N O_{2}}{S_{2}}<1
$$

...where $\mathrm{NO}_{3}$ is nitrate concentration $(\mathrm{mg} / \mathrm{L}), \mathrm{S}_{1}$ is the allowable value of $\mathrm{NO}_{3}$ based on $\mathrm{WHO}(\mathrm{mg} / \mathrm{L}), \mathrm{NO}_{2}$ is the nitrate concentration $(\mathrm{mg} / \mathrm{L}), \mathrm{S}_{2}$ is the allowable value of $\mathrm{NO}_{2}$, and $\mathrm{K}$ is sum of the relative values of $\mathrm{NO}_{3}$ and $\mathrm{NO}_{2}$.

Continuous monitoring of groundwater regarding pollutants determines the amount and intensity of pollutants. Moreover, it shows the necessary solutions to schedule and decrease negative effects of these pollutants for water resource planning. Geographical information system (GIS) is a useful and effective tool for saving data, showing spatial data, analyzing parameters spatially, and integrating for desirable output that can be used for decision making in various fields such as environmental protection [18-20]. In the current study, pollution of Ardabil aquifer groundwater in terms of $\mathrm{NO}_{3}, \mathrm{NO}_{2}$, and heavy metals was investigated and analyzed. Ardabil aquifer is located in Ardabil Province (one of the most important agricultural regions in Iran), and $\mathrm{N}$ fertilizer usage on agricultural lands has been increased significantly in this province. Additionally, sewage disposal in this province is through absorbent wells, thus exposing groundwater to pollution in this province. Ardabil is one of the industrial centers of Iran and in recent years groundwater resources in these regions have been in danger of heavy metals pollution because of industrial activities. Therefore, the purpose of this study is to evaluate $\mathrm{NO}_{3}$ and $\mathrm{NO}_{2}$ content in groundwater of Ardabil aquifer using three water standard qualifiers, including WHO [21], EPA [22], and ISIRI [23] to determine their spatial distribution through geostatistical approach and GIS. In addition to analyzing $\mathrm{NO}_{3}$ and $\mathrm{NO}_{2}$, some heavy metals pollution indices were selected and investigated for the study area.

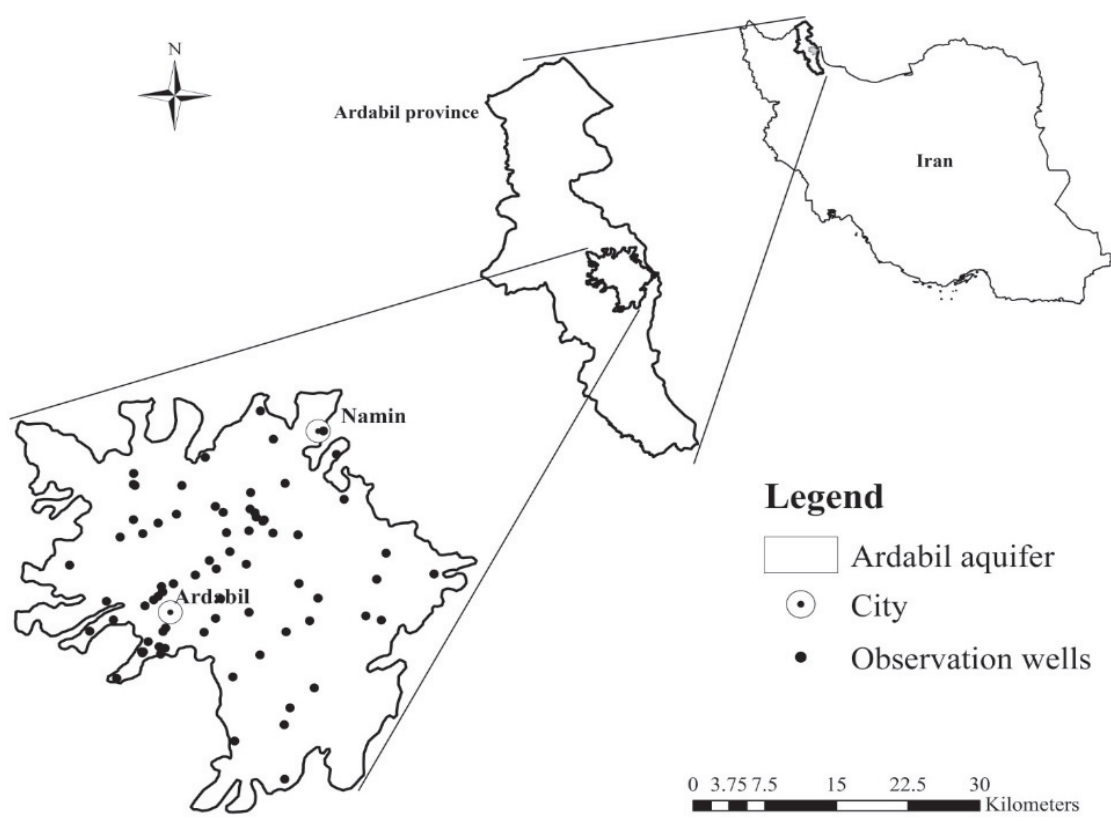

Fig. 1. Location of the study area and wells for monitoring $\mathrm{NO}_{3}$ and $\mathrm{NO}_{2}$ pollution at Ardabil Aquifer in Ardabil Province. 


\section{Materials and Methods}

\section{Study Area}

The study area was located in Ardabil Province, which is $17,953 \mathrm{~km}^{2}$ (1.09\% of Iran) and located in northwestern Iran between $37.45^{\circ}-39.42^{\circ}$ north latitudes and $48.55^{\circ}-47.30^{\circ}$ east longitudes. The groundwater of Ardabil Aquifer included Ardabil and Namin cities with areas of about $1,153 \mathrm{~km}^{2}$. Fig. 1 shows the study area location.

From a hydrological perspective, the study area is part of the Gare-Soo watershed. The rivers that have a direct effect on Ardabil Aquifer including Gare-Soo, BalikhlooChay, and Kuri-Chay. Regarding available facilities such as industrial parks and accessibility to neighboring countries' markets, Ardabil has turned into an industrial center in Iran. Additionally, due to the climate and soil fertility, this region is considered one of the country's main agricultural centers, meaning that chemical fertilizer use for agricultural purposes affects the pollution rate of groundwater. In order to monitor the pollution of $\mathrm{NO}_{3}$, $\mathrm{NO}_{2}$, and some heavy metals, 76 wells were considered in the study area and sampling and testing were performed during two seasons, including dry and wet seasons in 2011. In order to investigate heavy metals concentrations, the following metals were measured: mercury $(\mathrm{Hg})$, cadmium $(\mathrm{Cd})$, chromium $(\mathrm{Cr})$, copper $(\mathrm{Cu})$, iron $(\mathrm{Fe})$, manganese $(\mathrm{Mn})$, nickel $(\mathrm{Ni})$, lead $(\mathrm{Pb})$, zinc $(\mathrm{Zn})$, arsenic $(\mathrm{As})$, and antimony $(\mathrm{Sb})$. The dry season sampling was conducted at minimum groundwater conditions in October 2011 and wet season sampling was conducted at maximum level of groundwater conditions in April 2011. Among the 76 existing wells, 32 were used as drinking wells and 44 were agricultural wells. Fig. 1 shows the location of wells within the study area. In this research, $\mathrm{NO}_{3}$ and $\mathrm{NO}_{2}$ parameters were zoned for spatial analysis by using the geostatistics toolbox in ArcGIS. However, heavy metals pollution was evaluated using heavy metals pollution indices.

\section{Statistical and Geostatistical Analysis}

We used geostatistical approaches to investigate spatial analysis of $\mathrm{NO}_{3}$ and $\mathrm{NO}_{2}$. Geostatistical approaches are used widely for studying water quality. In this approach, by spatial continuity analysis, water quality analysis was performed. According to a literature review, the Kriging interpolation method was the most exact method with the lowest error rate and was chosen as the most appropriate method of interpolation [24]. Kriging performance in interpolating parameters depends on carefully choosing the semivariogram. For zoning and spatial distribution of pollutants, it is necessary to have variable spatial consistency as described by a semivariogram. The main purpose of calculating a semivariogram is to know variability terms of spatial distance. Each variogram has important characteristics. The value of a variogram for $h$ $=0$ (the beginning of coordination) is called a nugget $\left(\mathrm{c}_{0}\right)$. Ideally, the value of $c_{0}$ must be zero, but it is often more than zero. The reasons for the nugget include random components in variable distribution, sampling errors, and preparation and analysis of data. Random components of variable distribution cause a kind of short discontinuity in the domain that appears in $\mathrm{c}_{0}$. The more variable distribution that is random with less continuity, the bigger the $c_{0}$ [24]. The least distance between variogram and constant value is called domain or range (R). The domain defines the range of data that can be used to estimate the values of the unknown variables. The bigger $\mathrm{R}$ indicates wider spatial consistency. The stable value of a variogram is called sill $\left(\mathrm{c}_{0}+\mathrm{c}\right)$. The sill value is equal to the variance of data used in the semivariogram. In the kriging method, variograms that have a distinctive sill are more important. The nugget ratio on sill $\left(\mathrm{c}_{0} / \mathrm{c}_{0}+\mathrm{c}\right)$ can be a criterion for classifying variable spatial dependency. If this ratio is less than 0.25 , there is a strong spatial dependency. If this ratio is between 0.25 and 0.75 , there is a medium spatial dependency, and if it is greater than 0.75 there is weak spatial dependency. Strong spatial dependency means that the unknown variable can be estimated in the effect range $[15,25-26]$. The semivariogram may be mathematically described as the mean square variability between two neighboring points of distance as shown in Eq. 2 [27]:

$$
\gamma(\mathrm{h})=\frac{1}{2 \mathrm{~N}(\mathrm{~h})} \sum_{\mathrm{i}=1}^{\mathrm{N}(\mathrm{h})}\left[\mathrm{z}\left(\mathrm{x}_{\mathrm{i}}+\mathrm{h}\right)-\mathrm{z}\left(\mathrm{x}_{\mathrm{i}}\right)\right]^{2}
$$

...where $\gamma(\mathrm{h})$ is represented by a semivariogram as a function of the magnitude of the lag distance or separation vector $h$, which falls between two points; $N(h)$ is the number of observation pairs separated by distances of $h$ and $\mathrm{z}\left(\mathrm{x}_{\mathrm{i}}\right)$; and the random variable will be at the $\mathrm{x}_{\mathrm{i}}$ location. The $\gamma(\mathrm{h})$ is fitted to a theoretical model such as spherical, exponential, or Gaussian to determine model parameters including the nugget $\left(\mathrm{c}_{0}\right)$, sill $\left(\mathrm{c}+\mathrm{c}_{0}\right)$, and range $(\mathrm{R})$. These models are expressed with the following equations:

$$
\begin{array}{ll}
\gamma(\mathrm{h})=\mathrm{c}_{0}+\left[1.5\left(\frac{\mathrm{h}}{\mathrm{R}}\right)-0.5\left(\frac{\mathrm{h}}{\mathrm{R}}\right)^{3}\right] & \mathrm{h} \leq \mathrm{R} \\
\gamma(\mathrm{h})=\mathrm{c}_{0}+\mathrm{c}, & \mathrm{h}>\mathrm{R} \\
\text { Spherical model } &
\end{array}
$$

$$
\gamma(h)=c_{0}+c\left[1-\exp \left(-3 \frac{h}{R}\right)\right]
$$

Exponential model

$$
\gamma(\mathrm{h})=\mathrm{c}_{0}+\mathrm{c}\left[1-\exp \left[-\left(\frac{3 \mathrm{~h}}{\mathrm{R}}\right)^{2}\right]\right]
$$

Gaussian model

In this study, the simple Kriging method was chosen because of hypotheses such as: dependency of mean from coordinate, non-trendiness, distinctiveness of the mean, and having less error than other interpolation methods. 
Interpolation of the Kriging method is as follows:

$$
z\left(x_{0}\right)=m+\sum_{i=1}^{n} \lambda_{i}\left[z\left(x_{i}\right)-m\right]
$$

...where $\mathrm{m}$ stands for the mean, $\lambda_{\mathrm{i}}$ is weight, $\mathrm{z}\left(\mathrm{x}_{\mathrm{i}}\right)$ is measured value, and $\mathrm{z}\left(\mathrm{x}_{0}\right)$ is estimated value. In the current study we used the Kolmogorov-Smirnov test for data normalization, which is one of the constraints of a variogram. In order to draw zoning maps we used Arc GIS 10.3. An optimized semivariogram model with values of its parameters (nugget, domain, sill) was determined as the criterion for performance evaluation of a model [15]. Performance evaluations of the fitted models were checked on the basis of cross validation tests. The coefficient of determination $\left(\mathrm{R}^{2}\right)$, root mean square errors (RMSE), mean square error (MSE), mean absolute error (MAE), and normalized root mean square error (NRMSE) statistics were utilized to evaluate the employed models [27]:

$$
\begin{aligned}
& \text { RMSE }=\sqrt{\frac{\sum_{i=1}^{\mathrm{n}}\left(\vartheta_{\mathrm{cal}}-\vartheta_{\mathrm{obs}}\right)^{2}}{\mathrm{~N}}} \\
& \mathrm{MSE}=\frac{\sum_{\mathrm{i}=1}^{\mathrm{n}}\left(\vartheta_{\mathrm{obs}}-\vartheta_{\mathrm{cal}}\right)^{2}}{\mathrm{~N}} \\
& \mathrm{MAE}=\frac{\sum_{\mathrm{i}=1}^{\mathrm{n}}\left|\vartheta_{\mathrm{obs}}-\vartheta_{\mathrm{cal}}\right|}{\mathrm{N}} \\
& \mathrm{NRMSE}=\frac{\mathrm{RMSE}}{\mathrm{N}} \times 100
\end{aligned}
$$

...where $\vartheta_{\text {cal }}$ is estimated value, $\vartheta_{\text {obs }}$ is observed value, and $\mathrm{N}$ is the number of points. The ideal percent for modeling is less than $10 \%$ of the NRMSE statistic. The range of $10 \%$ to $20 \%$ and $20 \%$ to $30 \%$ of NRMSE indicates appropriate and moderate conditions in a model prediction, respectively, and more than $30 \%$ indicates uncertainty of the modeling.

\section{Heavy Metal Pollution Index (HPI)}

HPI is an important index for assessing heavy metals pollution in groundwater and surface water [28]. It is a weighing method that shows the combined effects of each heavy metal on final water quality. In the weighing system, the weight values are between 0 and 1 and choosing this system depends on the importance of each metal. These values can be calculated through standard reverse $(1 / \mathrm{Si})$ [28-29]. HPI is calculated by Eq. 11 [29]:

$$
\mathrm{HPI}=\frac{\sum_{\mathrm{i}=1}^{\mathrm{n}} \mathrm{W}_{\mathrm{i}} \mathrm{Q}_{\mathrm{i}}}{\sum_{\mathrm{i}=1}^{\mathrm{n}} \mathrm{W}_{\mathrm{i}}}
$$

...where $Q_{i}$ stands for sub index of the $i^{\text {th }}$ parameter, $W_{i}$ is the unit weight of the $\mathrm{i}^{\text {th }}$ parameter, and $n$ is the number of parameters considered. The sub index $\left(\mathrm{Q}_{\mathrm{i}}\right)$ of the parameter is calculated by Eq. 12:

$$
\mathrm{Q}_{\mathrm{i}}=\sum \frac{\left\{\mathrm{M}_{\mathrm{i}}(-) \mathrm{I}_{\mathrm{i}}\right\}}{\left(\mathrm{S}_{\mathrm{i}}-\mathrm{I}_{\mathrm{i}}\right)} \times 100
$$

...where $\mathrm{M}_{\mathrm{i}}$ is the monitored value of heavy metal of the $i^{\text {th }}$ parameter, $I_{i}$ is the ideal value of the $i^{\text {th }}$ parameter (the maximum desirable value for drinking water), $\mathrm{S}_{\mathrm{i}}$ is the standard value of the $i^{\text {th }}$ parameter (highest permissive value for drinking water), and (-) shows the numerical difference between the two values. The critical value of HPI for drinking water is 100 [30]. HPI can be classified into three categories: high, medium, and low. High stands for greater than 30, medium for between 15 and 30, and low for less than 15 [31]. In this research we used the ISIRI standard for HPI evaluation (which is the same as the WHO standard).

\section{Heavy Metal Evaluation Index (HEI)}

HEI is another index that shows water quality in terms of heavy metals values through Eq. 13:

$$
\mathrm{HEI}=\sum_{\mathrm{i}=1}^{\mathrm{n}} \frac{\mathrm{H}_{\mathrm{c}}}{\mathrm{H}_{\mathrm{mac}}}
$$

...where $\mathrm{H}_{c}$ is the monitored value of the $\mathrm{i}^{\text {th }}$ parameter, $\mathrm{H}_{\text {mac }}$ is the maximum allowable concentration of the $i^{\text {th }}$ parameter, and $\mathrm{n}$ is the number of measured heavy metals [32]. The HEI index is categorized into three levels of pollution, including low, medium, and high in accordance with values less than 40 , between 40 and 80 , and more than 80 , respectively [32].

$$
\text { Degree of Contamination }\left(\mathrm{C}_{\mathrm{d}}\right)
$$

Based on $\mathrm{C}_{\mathrm{d}}$, water quality is analyzed by calculating the degree of pollution by way of parameters that have values above the standard level. In other words, parameters that have values less than the permissible limit are not considered [33]. Because $C_{d}$ summarizes the combined effects of a number of parameters, it is regarded as unsafe for household water [34]. This index was developed by the Geological Organization of the Slovak Republic [35]. $\mathrm{C}_{\mathrm{d}}$ for each water sample was separately calculated according to Eqs 14 and 15 [36]: 


$$
\begin{gathered}
C_{d}=\sum_{i=1}^{n} C_{f i} \\
C_{f i}=\frac{C_{A i}}{C_{N i}}-1
\end{gathered}
$$

...where $\mathrm{C}_{\mathrm{fi}}$ represents contamination factor of the $\mathrm{i}^{\text {th }}$ parameter, $\mathrm{C}_{\mathrm{Ai}}$ is the analytical value of the $\mathrm{i}^{\text {th }}$ parameter, $\mathrm{C}_{\mathrm{Ni}}$ is the highest permissible concentration of the $\mathrm{i}^{\text {th }}$ parameter, and $n$ is the number of parameters (metals) that have values above the permissible limit. The values of $\mathrm{C}_{\mathrm{d}}$ in three pollution classes of low, medium, and high are respectively categorized into values of less than 1 , between 1 and 3 , and more than 3 .

\section{Results and Discussion}

According to the results in Table 1, $46 \%$ of wells in the dry season and $35 \%$ of wells in the wet season have total dissolved solids (TDS) above the standard level. PH in both wet and dry seasons is at allowable levels. Mean of the values $\mathrm{Na}, \mathrm{Mg}, \mathrm{C} 1, \mathrm{SO}_{4}$, and $\mathrm{HCO}_{3}$ is low in both seasons, but the coefficient of variation $(\mathrm{CV})$ of parameters $\mathrm{Na}, \mathrm{Mg}$, and $\mathrm{Cl}$ is high in the wet season, which shows the entrance of these elements into groundwater due to human activities such as wastewater or as a result of leaching elements in agriculture. The low rate of $\mathrm{CV}$ in other elements shows the ions' stability in groundwater. Table 2 shows the results of analytic analysis of $\mathrm{NO}_{3}, \mathrm{NO}_{2}$, and $\mathrm{k}$ values in groundwater of Ardabil aquifer. In this table, the highest, the lowest, standard deviation (SD), mean, and standard values of $\mathrm{NO}_{3}$ and $\mathrm{NO}_{2}$ in drinking water are presented according to WHO, ISIRI, and EPA standards. $\mathrm{NO}_{3}$ is one of the water pollutants that is an oxidized form of $\mathrm{N}$ compounds.
According to WHO and ISIRI, the allowable levels of $\mathrm{NO}_{3}$ and $\mathrm{NO}_{2}$ are 50 and $3 \mathrm{mg} / \mathrm{L}$, and according to the EPA these values are 10 and $1 \mathrm{mg} / \mathrm{L}$, respectively. Based on Table 2, the highest and the lowest values of $\mathrm{NO}_{3}$ in the dry season are 143.6 and $0.02 \mathrm{mg} / \mathrm{L}$, and in the wet season these values are 129.9 and $0.03 \mathrm{mg} / \mathrm{L}$, respectively. The highest value of observed $\mathrm{NO}_{2}$ in one well is $4.1 \mathrm{mg} / \mathrm{L}$, whereas in the other wells the value of this substance is less than $1 \mathrm{mg} / \mathrm{L}$. Regarding WHO and ISIRI standards, 10.5 percent of wells and, in respect to the EPA, $69.7 \%$ of wells have an amount of $\mathrm{NO}_{3}$ higher than the standard level in the wet season. On the other hand, in the dry season, concerning WHO and ISIRI standards, about 29 and based on EPA, $80.6 \%$ of wells have amounts of $\mathrm{NO}_{3}$ above the standard level; conversely, according to all standards, the amount of $\mathrm{NO}_{2}$ is less than the allowable level for drinking consumption.

In the dry season, $\mathrm{NO}_{3}$ and $\mathrm{NO}_{2}, \mathrm{CV}$, and $\mathrm{K}$ were calculated at $84.4 \%, 340.9 \%$, and $84 \%$, respectively. One of the most important reasons of Ardabil groundwater pollution is related to non-point pollution due to chemical fertilizers in agriculture. According to Table 2, the highest values of $\mathrm{K}$ measured in wet and dry seasons were reported as 2.87 and 2.81, respectively, and evaluated means were 0.8 and 0.51 . In the dry season $29 \%$ and in wet season $13.15 \%$ of the wells had $\mathrm{K}$ values more than 1 , and it is in the standard range regarding all standards. However, measurements conducted in the wet season demonstrated that the values of $\mathrm{NO}_{2}$ were more than 1 in only one well (about $4.11 \mathrm{mg} / \mathrm{L}$ ), and in other wells it was less than 1 . Regarding the values of $\mathrm{NO}_{2}$ less than the standard level in both seasons (except well 1), the spatial distribution of this parameter was avoided. The results of this study revealed that the values of $\mathrm{NO}_{2}$ in the investigated range are less than the recommended standard level. A high concentration of $\mathrm{NO}_{3}$ along with a low concentration of $\mathrm{NO}_{2}$ show that the pollution hasn't happened recently and momentarily, but this increase has occurred during many years. This trend will continue unless necessary controlling actions are taken.

Table 1. Statistical parameters of chemical contents of groundwater of Ardabil Aquifer (in terms of mg/L except pH).

\begin{tabular}{|c|c|c|c|c|c|c|c|c|c|c|}
\hline \multirow{2}{*}{ Parameter } & \multicolumn{9}{|c|}{ Dry season } & \multicolumn{4}{c|}{ Wet season } \\
\cline { 2 - 13 } & Min & Max & Mean & SD & CV $(\%)$ & Min & Max & Mean & SD & CV $(\%)$ \\
\hline $\mathrm{TDS}$ & 148.0 & 3716.0 & 1011.9 & 648.9 & 64.1 & 92.0 & 12772.0 & 1117.1 & 1541.6 & 138.0 \\
\hline $\mathrm{Ca}$ & 0.6 & 43.8 & 16.2 & 8.6 & 52.7 & 1.3 & 117.1 & 11.6 & 14.9 & 128.1 \\
\hline $\mathrm{Na}$ & 2.4 & 62.1 & 16.2 & 11.3 & 70.0 & 0.0 & 211.2 & 16.6 & 24.7 & 148.3 \\
\hline $\mathrm{K}$ & 0.0 & 21.8 & 2.7 & 4.2 & 155.5 & 0.0 & 13.8 & 2.4 & 2.6 & 109.8 \\
\hline $\mathrm{Mg}$ & 0.1 & 21.1 & 5.1 & 3.9 & 77.8 & 0.1 & 63.3 & 5.8 & 9.5 & 163.3 \\
\hline $\mathrm{Cl}$ & 2.1 & 107.7 & 18.7 & 16.9 & 90.7 & 0.9 & 201.2 & 19.0 & 25.3 & 133.2 \\
\hline $\mathrm{SO}_{4}$ & 0.0 & 19.7 & 37.7 & 33.4 & 88.6 & 0.4 & 161.2 & 31.5 & 28.8 & 91.5 \\
\hline $\mathrm{HCO}_{3}$ & 218.8 & 101.4 & 47.8 & 15.6 & 32.6 & 9.6 & 106.3 & 39.5 & 21.9 & 55.5 \\
\hline $\mathrm{pH}$ & 6.4 & 8.2 & 7.5 & 0.3 & 4.3 & 6.4 & 8.2 & 7.4 & 0.4 & 5.6 \\
\hline
\end{tabular}


Table 2. Statistical calculations of $\mathrm{NO}_{3}, \mathrm{NO}_{2}$, and $\mathrm{K}$ in wet and dry seasons.

\begin{tabular}{|c|c|c|c|c|c|c|}
\hline \multirow{2}{*}{ Inspection term } & \multicolumn{3}{|c|}{ Dry season } & \multicolumn{3}{c|}{ Wet season } \\
\cline { 2 - 7 } & $\begin{array}{c}\mathrm{NO}_{3} \\
(\mathrm{mg} / \mathrm{L})\end{array}$ & $\begin{array}{c}\mathrm{NO}_{2} \\
(\mathrm{mg} / \mathrm{L})\end{array}$ & $\begin{array}{c}\mathrm{K} \\
(-)\end{array}$ & $\begin{array}{c}\mathrm{NO}_{3} \\
(\mathrm{mg} / \mathrm{L})\end{array}$ & $\begin{array}{c}\mathrm{NO}_{2} \\
(\mathrm{mg} / \mathrm{L})\end{array}$ & $\begin{array}{c}\mathrm{K} \\
(-)\end{array}$ \\
\hline Max & 143.6 & 0.6 & 2.9 & 129.9 & 4.1 & 2.8 \\
\hline Min & 0.02 & 0.01 & 0.012 & 0.03 & 0.01 & 0.013 \\
\hline mean & 39.7 & 0.2 & 0.8 & 23.6 & 0.1 & 0.5 \\
\hline SD & 33.6 & 0.075 & 0.7 & 23.4 & 0.5 & 0.5 \\
\hline CV (\%) & 84.4 & 340.9 & 84.0 & 99.2 & 480.0 & 103.6 \\
\hline EPA standard & 10.0 & 1.0 & - & 10.0 & 1.0 & - \\
\hline WHO standard & 50.0 & 3.0 & 1.0 & 50.0 & 3.0 & 1.0 \\
\hline $\begin{array}{c}\text { ISIRI standard } \\
\text { EPA over standard } \\
(\%)\end{array}$ & 50.0 & 3.0 & - & 50.0 & 3.0 & - \\
\hline $\begin{array}{c}\text { WHO over standard } \\
(\%)\end{array}$ & 29.0 & - & - & 69.7 & - & - \\
\hline $\begin{array}{c}\text { ISIRI over standard } \\
(\%)\end{array}$ & 29.0 & - & 29.0 & 10.5 & - & - \\
\hline
\end{tabular}

Table 3. Results of geostatistical analysis of $\mathrm{NO}_{3}$ parameters in wet and dry seasons.

\begin{tabular}{|c|c|c|c|c|c|c|}
\hline \multirow[b]{2}{*}{ Parameter } & \multirow[b]{2}{*}{ Order of trend } & \multirow[b]{2}{*}{ Model } & \multicolumn{4}{|c|}{ Errors } \\
\hline & & & $\begin{array}{l}\text { RMSE } \\
(\mathrm{mg} / \mathrm{L})\end{array}$ & $\begin{array}{c}\mathrm{MSE} \\
(\mathrm{mg} / \mathrm{L})\end{array}$ & $\begin{array}{c}\text { MAE } \\
(\mathrm{mg} / \mathrm{L})\end{array}$ & $\begin{array}{c}\text { NRMSE } \\
(\%)\end{array}$ \\
\hline \multirow{9}{*}{$\begin{array}{c}\mathrm{NO}_{3} \\
\text { (dry season) }\end{array}$} & \multirow{3}{*}{ None } & Gaussian & 21.70 & 470.99 & 16.43 & 11.82 \\
\hline & & Spherical & 21.79 & 475.21 & 16.43 & 11.93 \\
\hline & & Exponential & 22.20 & 492.96 & 16.68 & 12.37 \\
\hline & \multirow{3}{*}{ First } & Gaussian & 21.91 & 480.35 & 16.17 & 12.06 \\
\hline & & Spherical & 22.06 & 486.71 & 16.18 & 12.22 \\
\hline & & Exponential & 22.46 & 504.88 & 16.44 & 12.67 \\
\hline & \multirow{3}{*}{ Second } & Gaussian & 22.31 & 497.64 & 16.21 & 12.49 \\
\hline & & Spherical & 22.46 & 504.43 & 16.23 & 12.66 \\
\hline & & Exponential & 22.80 & 520.06 & 16.45 & 13.05 \\
\hline \multirow{9}{*}{$\begin{array}{c}\mathrm{NO}_{3} \\
\text { (wet season) }\end{array}$} & \multirow{3}{*}{ None } & Gaussian & 21.08 & 444.59 & 13.42 & 18.98 \\
\hline & & Spherical & 21.23 & 450.74 & 13.70 & 19.24 \\
\hline & & Exponential & 21.51 & 462.91 & 14.04 & 19.76 \\
\hline & \multirow{3}{*}{ First } & Gaussian & 23.18 & 537.39 & 14.27 & 22.94 \\
\hline & & Spherical & 23.17 & 537.14 & 14.29 & 22.93 \\
\hline & & Exponential & 22.74 & 516.98 & 14.09 & 22.07 \\
\hline & \multirow{3}{*}{ Second } & Gaussian & 24.31 & 591.22 & 15.17 & 25.24 \\
\hline & & Spherical & 24.28 & 589.59 & 15.19 & 25.17 \\
\hline & & Exponential & 23.48 & 551.56 & 14.79 & 23.55 \\
\hline
\end{tabular}


Table 4. Optimal parameters of semivariogram model.

\begin{tabular}{|c|c|c|c|c|c|c|c|c|c|c|}
\hline & Trend & Model & $\begin{array}{c}\text { Range } \\
(\mathrm{m})\end{array}$ & $\begin{array}{c}\text { Nugget } \\
\left(\mathrm{c}_{0}\right)\end{array}$ & $\begin{array}{c}\text { Sill } \\
(\mathrm{c}+\mathrm{c})\end{array}$ & $\mathrm{c}_{0} / \mathrm{c}_{0}+\mathrm{c}$ & $\begin{array}{c}\text { RMSE } \\
(\mathrm{mg} / \mathrm{L})\end{array}$ & $\begin{array}{c}\text { MSE } \\
(\mathrm{mg} / \mathrm{L})\end{array}$ & $\begin{array}{c}\text { MAE } \\
(\mathrm{mg} / \mathrm{L})\end{array}$ & $\begin{array}{c}\text { NRMSE } \\
(\%)\end{array}$ \\
\hline $\begin{array}{c}\text { type } \\
\text { (dry season) }\end{array}$ & None & Gaussian & $1,683.96$ & 234.71 & 816.94 & 0.28 & 21.70 & 470.99 & 16.43 & 11.82 \\
\hline $\begin{array}{c}\mathrm{NO}_{3} \\
\text { (wet season) }\end{array}$ & None & Gaussian & $9,073.60$ & 166.73 & 332.12 & 0.50 & 21.08 & 444.58 & 13.42 & 18.98 \\
\hline
\end{tabular}

\section{Variogram Analysis}

Cross validation results of spherical, Gaussian, and exponential models are presented in Table 3. A comparison of the results indicates that the Gaussian method with the least rate of error was an optimized method for spatial representation of parameters. Therefore, all the variograms were described using this model. Mehrjardi et al. [37] and Bian et al. [11] showed that spherical and Gaussian models can better describe spatial continuity of groundwater quality. The characteristics of an optimized variogram drawing model are presented in Table 4. Values of $\mathrm{C}_{0} /$ $\mathrm{C}_{0}+\mathrm{C}$ indicate that between $\mathrm{NO}_{3}$ parameters in the dry season there is a strong spatial continuity, and in the wet season there is a medium spatial continuity. Variograms related to measured components are presented in Fig. 2.

Regarding results in Table 4 and according to all tests, the Kriging interpolation method is an appropriate and exact method for estimating and zoning the measured components. Mehrjardi et al. [37] and Fetouani et al. [38] also have introduced Kriging as a more appropriate method for estimating components and zoning parameters. Also, in this study, Kriging was the most accurate method used for interpolation. Fig. 3 presents a zoning map of $\mathrm{NO}_{3}$ ions.

According to Table 3 and WHO standards, in the wet season the Namin area and south Ardabil have values of $\mathrm{NO}_{3}$ above the standard level. However, in the dry season these areas have low values of $\mathrm{NO}_{3}$. The reason for this can be the pollution due to $\mathrm{N}$ fertilizers leaching from agricultural fields in the wet season. In the dry season in Ardabil, which has the most drinking-water wells, there are high values of $\mathrm{NO}_{3}$. This can be due to a decrease in rain, relatively high evaporation, and an increase in element concentrations. In the other words, the values of $\mathrm{NO}_{3}$ increase with a decreasing water table. Related to the EPA, central areas of study in the wet season have low values of $\mathrm{NO}_{3}$ and in the dry season small parts in the central region possess low values of $\mathrm{NO}_{3}$. According to the recommended WHO formula, the total ratios of measured values of the proposed standard values $(\mathrm{K})$ is another criterion for $\mathrm{NO}_{3}$ and $\mathrm{NO}_{2}$ being evaluated simultaneously for drinking water. Zoning values of $\mathrm{k}$ in the study area for wet and dry seasons are presented in Fig. 4.

According to Fig. 4, in the wet season in the Namin area (the center and the south of the study area), $\mathrm{K}$ value is more than 1. Also, in the dry season, in the city of Ardabil, $\mathrm{K}$ is higher than 1 . In other areas, $\mathrm{K}$ is less than the allowable level, which is indicated by the results of Fig. 4 in accordance with Fig. 3 ( $\mathrm{NO}_{3}$ zoning).

\section{Evaluating Heavy Metal Pollution Indexes}

Pollution indexes are very useful for providing an overview of water quality and in terms of considering different pollutants. For this purpose, HPI, HEI, and $\mathrm{C}_{d}$ pollution indexes were applied in this study. The results of categorizing Ardabil groundwater by sampling two
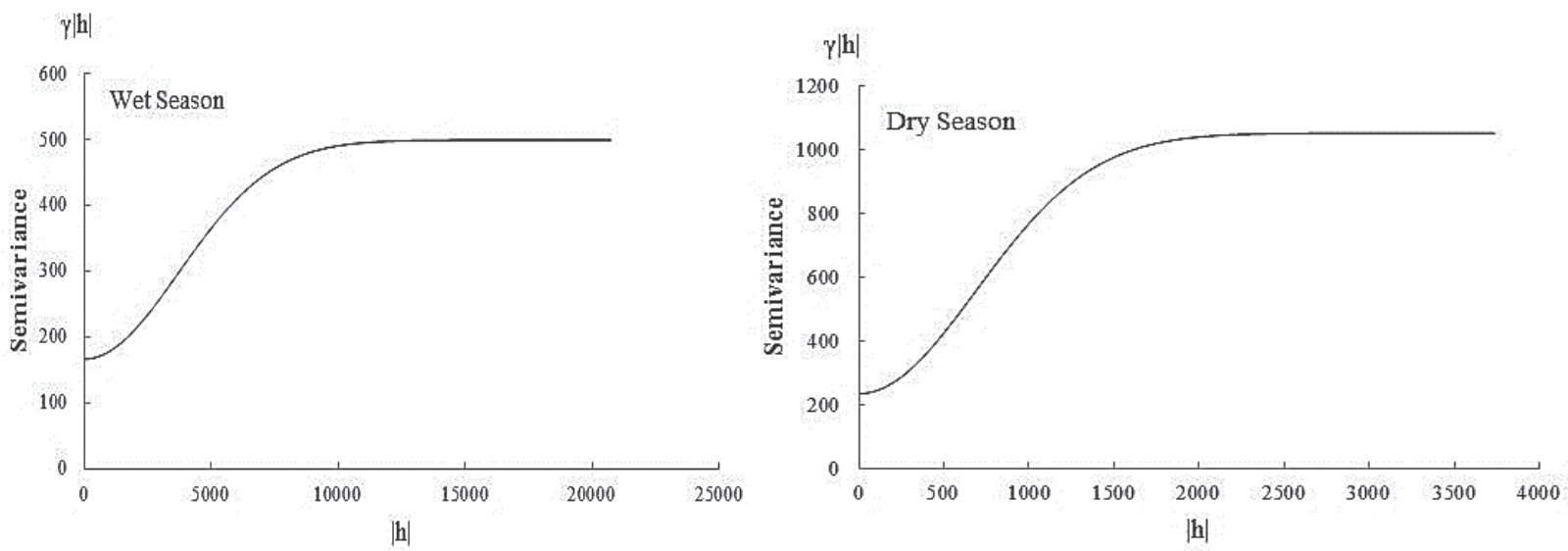

Fig. 2. Best-fitted semivariogram model of $\mathrm{NO}_{3}$ in two measurements of wet and dry seasons in Ardabil Aquifer (horizontal access is based on meters). 


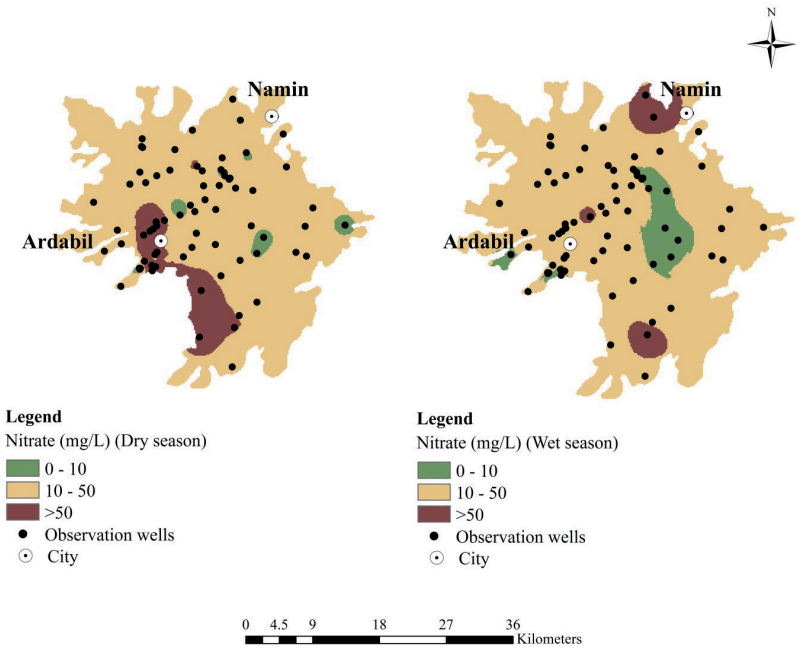

Fig. 3. Spatial distribution of $\mathrm{NO}_{3}$ in groundwater of Ardabil Aquifer.
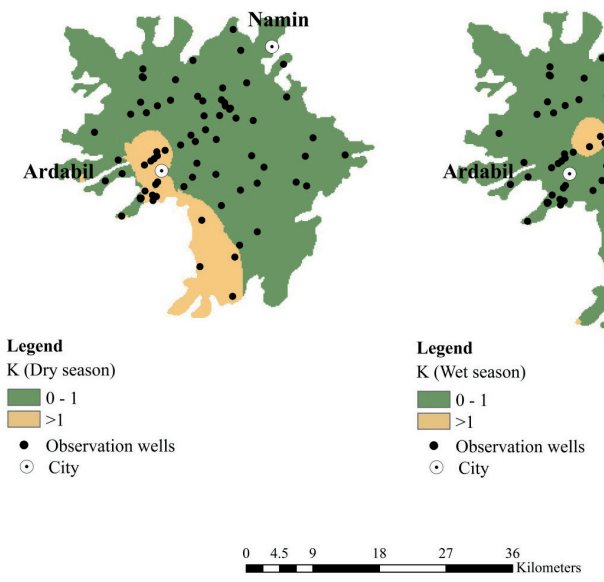

Fig. 4. Spatial distribution of measured ratios of $\mathrm{NO}_{3}$ and $\mathrm{NO}_{2}$ to standard values $(\mathrm{K})$.

times and based on the heavy metal pollution indexes are presented in Table 5. Based on the HPI index in dry and wet seasons, more than $80 \%$ of the wells are categorized as high class, whereas in the wet season about $88 \%$ of the wells are considered high class. The reason for a higher index in the wet season than the dry season is that the metals with high weights (such as As and $\mathrm{Pb}$ ) are in higher values in wet season than the dry season. Thus, this leads to a higher index in the wet season. The high value of HPI in the study area mainly has a source of human activity (as a result of using chemical fertilizers and not refining industrial wastewater). HEI is another index for analyzing heavy metal pollution. In this index, all the heavy metals are assumed to have the same weight in pollution rate; in spite of this, some of the metals have more effect on human health and more effect on pollution rates as well. Not allocating weights to the metals is one of the weaknesses of the HEI method. According to HEI,
Table 5. Classification of groundwater based on HPI, HEI, and $\mathrm{C}_{\mathrm{d}}$.

\begin{tabular}{|c|c|c|c|c|}
\hline \multirow{3}{*}{ Index } & Description & Class & $\begin{array}{c}\text { Dry of } \\
\text { samples }\end{array}$ & $\begin{array}{c}\text { \% of } \\
\text { samples }\end{array}$ \\
\hline \multirow{3}{*}{ HPI } & Low & $<15$ & 17.74 & 8.00 \\
\cline { 2 - 5 } & Medium & $15-30$ & 1.60 & 4.00 \\
\cline { 2 - 5 } & High & $>30$ & 80.64 & 88.00 \\
\hline \multirow{3}{*}{ HEI } & Low & $<40$ & 85.48 & 73.33 \\
\cline { 2 - 5 } & Medium & $40-80$ & 6.45 & 16.00 \\
\cline { 2 - 5 } & High & $>80$ & 8.07 & 10.66 \\
\hline \multirow{3}{*}{$C_{d}$} & Low & $<1$ & 6.45 & 2.60 \\
\cline { 2 - 5 } & Medium & $1-3$ & 3.22 & 4.00 \\
\cline { 2 - 5 } & High & $>3$ & 90.32 & 93.40 \\
\hline
\end{tabular}

in the dry season $85.48 \%$ of the samples are in a low class, $6.45 \%$ of them are in a medium class, and $8.07 \%$ is the low class. In wet season, $73.3 \%$ of samples are in low, $16 \%$ are in medium and $10.66 \%$ are in high classes. In the dry season, all the metals are in higher values than the wet season. The results of HEI analysis have a contradictory result compared with HPI analysis. Also, according to a study of Jahanshahi and Zare [33], similar results have been reported. The $C_{d}$ index is also used for estimating heavy metal pollution rate. In calculating this index, those parameters that have less value than the permissible limit are not considered. According to this index, more than $90 \%$ of the samples are in a high class. Relating to this index, some metals with lower concentration levels than permissible limits are not considered, and all the samples are categorized into high class accordingly. Generally, HPI is a more accurate method in calculating heavy metal pollution due to its consideration of the weight for each parameter.

\section{Conclusions}

Regarding the importance of $\mathrm{NO}_{3}$ in drinking water and because of having long-term and short-term negative effects on humans, this study was conducted in the Ardabil Aquifer. For determining spatial distribution of water quality parameters, maps that have enough accuracy and geostatistical methods can be used. In the presented research, the Kriging method was used for zoning $\mathrm{NO}_{3}$ since a comparison of interpolation methods showed that this method has less error than other methods in zoning groundwater quality characteristics. Results revealed that the values of $\mathrm{NO}_{3}$ in the study area are higher than the values of $\mathrm{NO}_{2}$. One of the reasons for this is the high use of $\mathrm{N}$ chemical fertilizers for agriculture and vast industrial activities. The high values of $\mathrm{NO}_{3}$, despite the low values of $\mathrm{NO}_{2}$, shows that the existing pollution hasn't happened recently and momentarily, but it has happened over many years. 
Comparing zoning maps of $\mathrm{NO}_{3}$ in wet and dry seasons indicates that the values of $\mathrm{NO}_{3}$ in dry seasons is higher than in wet seasons. Therefore, it can be concluded that with a decrease in the water table, the concentration of $\mathrm{NO}_{3}$ increases. Generally, Ardabil Aquifer has a medium-to-undesirable pollution condition in terms of $\mathrm{NO}_{3}$ and $\mathrm{NO}_{2}$. Most drinking water wells are located in the city of Ardabil, which in the dry season has $\mathrm{NO}_{3}$ concentrations above the standard level, which requires remedial actions. However, in the suburbs of Ardabil itself, $\mathrm{NO}_{3}$ concentrations decrease in the wet season and reach the range of 10 to $50 \mathrm{mg} / \mathrm{L}$. With regard to $\mathrm{NO}_{3}$ and $\mathrm{NO}_{2}$, the importance for human health, necessary actions such as ion exchange, biological denitrification, chemical denitrification, electrodialysis, and reverse osmosis must be carried out in order to maintain $\mathrm{NO}_{3}$, and the polluted resources must be used for non-drinking and agriculture.

According to HPI and $\mathrm{C}_{\mathrm{d}}$, most parts are in highpollution classes, while according to HEI most regions are in a low class; this is because of considerations that parameters have the same effect on pollution rate. Therefore, it is recommended that people stop using wells for drinking, and that we refine heavy metals by using modern methods such as nano-filtration, ultra-nanofiltration, and reverse osmosis. Also, it is recommended that we develop a permanent monitoring network for investigating groundwater quality of the region.

\section{Acknowledgements}

The authors wish to express their sincere thanks to the Ardabil Environmental Conservation Office (AECO) for their cooperation, data providing, and assistance in facilitating the current study.

\section{References}

1. KUMARI S., SINGH A.K., VERMA A.K., YADUVANSHI N.P.S. Assessment and spatial distribution of groundwater quality in industrial areas of Ghaziabad, India. Environmental Monitoring and Assessment, 186 (1), 501, 2013.

2. KUMAR A., BOHRA C.P., SINGH L.K. Environment, pollution and management. APH Publishing Corporation, New Delhi, 2003.

3. NESTLER A., BERGLUND M., ACCOE F., DUTA S., XUE D., BOECKX P., TAYLOR P. Isotopes for improved management of nitrate pollution in aqueous resources: review of surface water field studies. Environmental Science and Pollution Research, 18 (4), 519, 2011.

4. JAYALAKSHMI S., VELAPPAN E. Assessment of water quality index in the St. Thomas Mount Block using GIS and remote sensing. Polish Journal of Environmental Studies, 24 (4), 1611, 2015.

5. CHEN S., WU W., HU K., Li W. The effects of land use change and irrigation water resource on nitrate contamination in shallow groundwater at county scale. Ecological Complexity, 7 (2), 131, 2010.
6. LOOP C.M., WHITE W.B. A conceptual model for DNAPL transport in karst ground water basins. Groundwater, 39 (1), 119, 2001.

7. WHITE W.B. Karst hydrology: recent developments and open questions. Engineering Geology, 65 (2), 85, 2002.

8. LU Y., TANG C., CHEN J., SAKURA Y. Impact of septic tank systems on local groundwater quality and water supply in the Pearl River Delta, China: Case study. Hydrological Processes, 22 (3), 443, 2008.

9. PUJARI P.R., NANOTI M., NITNAWARE V.C., KHARE L.A., THACKER N.P., KELKAR P.S. Effect of on-site sanitation on groundwater contamination in basaltic environment' A case study from India. Environmental Monitoring and Assessment, 134 (1-3), 271, 2007.

10. NSUBUGA F.B., KANSIIME F., OKOT-OKUMU J. Pollution of protected springs in relation to high and low density settlements in Kampala-Uganda. Physics and Chemistry of the Earth, 29 (15), 1153, 2004.

11. BIAN J., LIU C., ZHANG Z., WANG R., GAO Y. Hydrogeochemical characteristics and health risk evaluation of nitrate in groundwater. Polish Journal of Environmental Studies, 25 (2), 521, 2016.

12. KRAUS H.H. The European parliament and EC environment policy. European parliament, directorate-general for research, division for social affairs, the environment, consumer protection and public health, 1993.

13. XU K. Progress on three forms of nitrogen contaminant transport and transform in groundwater. Geotechnical Investigation and Surveying, 8, 008, 2012.

14. CHENG J., ZHANG H., ZHANG Y., CHEN Y., WANG B. Characteristics of preferential flow paths and their impact on nitrate nitrogen transport on agricultural land. Polish Journal of Environmental Studies, 23 (6), 1959, 2014.

15. AGCA N., KARANLIK S., ODEMIS B. Assessment of ammonium, nitrate, phosphate, and heavy metal pollution in groundwater from Amik Plain, southern Turkey. Environmental Monitoring and Assessment, 186 (9), 5921, 2014.

16. MERUSI C., CORRADINI C., CAVAZZA A., BORROMEI C., SALVADEO P. Analytical Methods; Determination of nitrates, nitrites and oxalates in food products by capillary electrophoresis with $\mathrm{pH}$-dependent electroosmotic flow reversal. Food Chemistry, 120 (2), 615, 2010.

17. HAMMER M.J. Water and Wastewater Technology. $5^{\text {th }}$ ed. Pearson Prentice Hall, Singapore, 137, 47, 2005.

18. NAS B. Geostatistical approach to assessment of spatial distribution of groundwater quality. Polish Journal of Environmental Studies, 18 (6), 1073, 2009.

19. BURROUGH P.A., McDonnell R.A. Principles of geographical information systems. Oxford University Press, 1998.

20. TIWARI A.K., DE MAIO M., SINGH P.K., MAHATO M.K. Evaluation of surface water quality by using GIS and a heavy metal pollution index (HPI) model in a coal mining area, India. Bulletin of Environmental Contamination and Toxicology, 95 (3), 304, 2015.

21. WHO. Guidelines for drinking-water quality, $4^{\text {th }}$ ed., World Health Organization, Geneva, Switzerland, 2011.

22. EPA. 2006 Edition of the drinking water standards and health advisories, U.S. Environmental Protection Agency, Washington, 2006.

23. ISIRI. Chemical specifications of drinking water. No. 1053, 5 th ed., Institute of Standards and Industrial Research of Iran, Tehran, 2009 [In Persian]

24. OSTOVARI Y., BEIGI H.H., DAVOODIAN A.R. Assessment, spatial variability and mapping of some 
water quality parameters for use in drip irrigation design in Lordegan plain, Iran. Iranian Journal of Irrigation and Drainage, 5 (2), 242, 2011 [In Persian]

25. CAMBARDELLA C.A., MOORMAN T.B., NOVAK J.M., PARKIN T.B., KARLEN D.L., TURCO R.F., KOROPAKA A.E. Field-scale variability of soil properties in central Iowa soils. Soil Science Society of America Journal, 58 (5), 1501, 1994.

26. CHIEN Y.J., LEE D.Y., GUO H.Y., HOUNG K.H. Geostatistical analysis of soil properties of mid-west Taiwan soils. Soil Science, 162 (4), 291, 1997.

27. ADHIKARY P.P., CHANDRASEKHARAN H., CHAKRABORTY D., KAMBLE K. Assessment of groundwater pollution in west Delhi, India using geostatistical approach. Environmental Monitoring and Assessment, 167 (1-4), 599, 2010.

28. KUMAR P.J.S., DELSON P.D., BABU P.T. Appraisal of heavy metals in groundwater in Chennai city using a HPI model. Bulletin of Environmental Contamination and Toxicology, 89 (4), 793, 2012.

29. MOHAN S.V., NITHILA P., REDDY S.J. Estimation of heavy metal in drinking water and development of heavy metal pollution index. Journal of Environmental Science and Health, Part A, 31 (2), 283, 1996.

30. PRASAD B., BOSE J. Evaluation of heavy metal pollution index for surface and spring water near a limestone mining area of the lower Himalayas. Environmental Geology, 41, 183, 2001.

31. TIWARI A.K., DE MAIO M., SINGH P.K., MAHATO M.K. Evaluation of surface water quality by using GIS and a heavy metal pollution index (HPI) model in a coal mining area, India. Bulletin of Environmental Contamination and Toxicology, 95 (3), 304. 2015.
32. BRRAICH O.S., JANGU S. Evaluation of water quality pollution indices for heavy metal contamination monitoring in the water of Harike wetland (Ramsar site), India. International Journal of Scientific and Research Publications, $5(2), 1.2015$.

33. JAHANSHAHI R., ZARE M. Assessment of heavy metal pollution in groundwater of Golgohar iron ore mine area, Iran. Environmental Earth Sciences, 74 (1), 505, 2015.

34. PRASANNA M.V., PRAVEENA S.M., CHIDAMBARAM S., NAGARJAN R., ELAYARAJA A. Evaluation of water quality pollution indices for heavy metal concentration monitoring: a case study from Curtin Lake, Miri City, East Malaysia. Environmental Earth Science, 67 (7), 2012.

35. BACKMAN B., BODIS D., LAHERMO P., RAPANT S., TARVAINEN T. Application of a groundwater contamination index in Finland and Slovakia. Environmental Geology, 36 (1-2), 55, 1997.

36. EDET A.E., OFFIONG O.E. Evaluation of water quality pollution indices for heavy metal contamination monitoring. A study case from Akpabuyo- Odukpani area, Lower Cross River Basin, (southeastern Nigeria). GeoJournal, 57 (4), 295. 2002.

37. MEHRJARDI R.T., JAHROMI M.Z., MAHMODI S., HEIDARI A. Spatial distribution of groundwater quality with geostatistics (Case study: Yazd-Ardakan plain). World Applied Sciences Journal, 4 (1), 9, 2008.

38. FETOUANI S., SBAA M., VANCLOOSTER M., BENDRA B. Assessing groundwater quality in the irrigated plain of Triffa (north-east Morocco). Agricultural Water Management, 95 (2), 133, 2008. 